\title{
Dealing with the media
}

An NHS manager was short and to the point when asked to comment on a potentially difficult issue in the press. To a press officer's question "What shall I tell the journalist?", he replied "Tell him not to print it". The extreme examples of media coverage that the NHS has recently received have led some doctors and managers to adopt a very low profile in the hopes that it will go away-an example is the reporting of five cases of necrotising fasciitis in Gloucestershire, which echoed round the world and led to such headlines as 50 million Americans at Risk, and Flesh Eating Bug Ate My Face Off.

Unfortunately, the press will almost certainly print a story anyway, and it will be worse if journalists have no access to authoritative sources. Apart from some of the national tabloid newspaper articles it is generally ignorance, admittedly sometimes wilful, that leads to the worse excesses. It is never helpful to be unavailable for comment. Although it may be too much to ask a doctor to appear in front of cameras to justify a misdiagnosis, it is vital that someone appears. Even with the restrictions of safeguarding patient confidentiality or the threat of legal action, it is usually still possible to express concern or to comment generally on activity that is taking place to establish if there has been a mistake.

\section{Deadlines}

Doctors working in accident and emergency departments have their own even more pressing deadlines to meet, and answering the questions of journalists can seem unimportant. However, any deadline missed in the media is a lost opportunity to put the facts straight, explain the context, express concern, and generally try to reassure the public.

Most larger towns have evening newspapers whose deadlines usually begin about 9 am for the first edition. The daily national and local newspaper staff work right through from late morning to midnight and later for front pages. The most pressing deadlines to meet are the hourly radio news bulletins. Do notbe pressurised into giving an interview instantly, however, but take five minutes to think of the two or three points that you want to make, and also to anticipate any facts that you will need to know.

\section{Coping with the big story!}

If your department becomes the focus of media attention the only way to exert any control is to work with the media by trying to accommodate them.

Allocate a room where they can wait and promise them that they will be kept informed of most changes. Give regular updates, even if there is no change. Their most important concern is that they will miss something new happening.

If you have a duty officer or a press officer, draft them in to try to control the press, but make sure that reporters have access to telephones to prevent them from wandering through the hospital.

There have been numerous incidents of reporters (mostly from national media) flouting all rules. In my region we have had many incidents, such as, a photogra- pher who dressed up as a doctor to try to photograph some Siamese twins, reporters who attempted to bribe porters in order to get access to medical records of celebrities, and many journalists posing as relatives of patients. Such behaviour can be very difficult to handle. Although there are various rulings from the regulatory bodies (for example, reporters cannot enter a hospital without revealing who they are and must not invade privacy gratuitously), this has not stopped them from doing so. Increasing the number of security guards, obtaining legal injunctions and other extreme measures can sometimes be the only solution. Luckily, however, most stories will be of interest mainly to the local press and their behaviour is usually far more reasonable, since they have to maintain relationships with their local hospitals.

\section{Talking to a reporter}

When using off the record briefings, where the reporter should not be quoting the material directly, or not for attribution, where you are not named as the source, you must be sure that these are reporters that you can trust. Your press officer should be able to advise you.

A really good, well informed journalist is a major asset and it is worth giving them as many of the facts as you can, but clarify the terms under which you are speaking to them. It has become more dangerous recently to use off the record briefings, however, and don't be lured into being too confiding, particularly with a camera running. Remember Gerald Ratner the jeweller, or John Major and his famous bastard speech.

\section{Gaining positive publicity}

There is a strong perception that the NHS only receives negative press attention, but a glance at any local paper or tuning in to any local radio station for a short time shows that positive NHS stories are featured daily. Health stories are full of human interest and, having worked in the world of commercial PR, I am amazed how easy it is to get coverage.

Timing is vital to obtain coverage for an item. If possible, aim to hold press conferences or other events in the late morning in the middle of the week. The best chance of attracting reporters from dailies is to run an 11 am press conference on Tuesdays or Wednesdays, and you will also make the final edition of the evening newspaper, and reach the weekly papers which often go to press on Wednesday.

\section{Broadcasting}

To attract coverage from television journalists you will need to provide opportunities for background filming of wards, laboratory scenes, patients, and so on to help them make up a package for the news or feature programmes.

It is very important to receive a short training session in broadcasting. The techniques are very easy to learn but are vital if you are to take control of an interview and achieve what you want. 
It is vital in any interview to avoid jargon and sounding defensive or aggressive, and to have the confidence to cease speaking when you have said what you wish.

In television it is almost as important how you convey a message as what you say. You must sound and look committed and enthusiastic, however difficult the interview, so that the viewer will feel confident that even if mistakes have been made something will be done to rectify it. Above all never sound complacent.

Body language is vital in colouring the message you convey to the audience. A training session will help you learn the importance of maintaining eye contact with the interviewer and the right way to sit or stand.

\section{Be philosophical!}

The press will not always cover a news item in the way you would like. They are there to question and to doubt the establishment, and doctors (sometimes) and managers (always) will be seen as part of this. Journalists also have to convey information on highly complex issues that can be understood by laymen. This can lead to distortion but rarely to complete inaccuracies. The motto sometimes cited for Public Relations applies equally to journaliststhey tell the truth, nothing but the truth, but never the whole truth.

\section{VICKI O'LOUGHLIN}

\section{Time management}

Fortunately for authors of articles, as with doctors in general, we are not rigidly forced to practice what we preach! Having wasted much time over the years I therefore make no claim to have emulated all of these pointers although many are being learnt the hard way or from others. Many trainees and consultants have had little management training; however, in clinical situations many time management skills such as prioritising and delegating are unwittingly employed. These skills need to be transferred to the office and in the new NHS are increasingly important.

The nature of $A \& E$, with few fixed clinical commitments compared to other specialties, and the low ratio of consultants to junior staff, means that at least $70 \%$ of our time is spent on management tasks such as personnel, rotas, guidelines and future planning.

\section{General principles}

"Lose an hour in the morning and you will be all day hunting for it" Richard Watley (1864)

(1) A sometimes difficult balance has to be struck between work, rest, and play, not forgetting the family and domestic issues. Work must be put in the context of whole life and can be greatly affected by stress, tiredness and family worries.

(2) Know your own tempo, work with the grain, and learn your own limitations.

(3) Do what you enjoy and are good at when you have the choice; this should help you decide on your commitment to various options such as research, audit, special interests, teaching and so forth.

(4) It is estimated that $20 \%$ of the effort yields $80 \%$ of the results, thus raising the question of what happens to the remaining $80 \%$ of the effort (the Pareto principle).

\section{Know your role and work responsibility}

Knowing what your job is may seem obvious but it is surprising how often we can become consumed with tasks which are not our main responsibility or even in our job description. Constantly ask yourself "What am I here for?" or "How does this task fit into my role?" and prioritise accordingly.

\section{Analyse activity}

(1) List and rank your main responsibilities and then work out the time spent on each and if it was appropriate.
(2) Record everything you do during a day and the time taken. For each task listed ask yourself the following questions:

Was it

Necessary? that is, your role and of any worth. What if you did not do it?

Appropriate for you to do or should it have been delegated? Efficient? Could it have been done quicker or by a better system?

These tests should be ruthlessly applied to your diary.

\section{Identify personal goals and objectives}

There will be some overlap with the above, but this area should include special interests/projects, areas of your department you are keen to improve, your own continuing education, or a service that you want to develop. Whether it is management training, life support teaching, or computer skills, your objectives for the time period must be listed and prioritised. Inevitably we do not allow for "unexpected" events or interruptions which must be incorporated into any plans.

\section{Prioritise-urgency and importance}

The following urgency/importance quadrants (fig 1) can be applied to tasks as well as to the paperwork on your desk.

For urgency consider if there is a deadline and if this is negotiable.

For importance consider if the task relates to your work objectives and whose needs it meets, that is, is it yours, your patients', your staffs', or your managers'.

$\mid$\begin{tabular}{ll} 
(File) & $\begin{array}{l}\text { (Act on) } \\
\text { high priority }\end{array}$ \\
DO IT LATER & DO IT NOW \\
$\begin{array}{l}\text { (bin it!) } \\
\text { low priority } \\
\text { DISCARD }\end{array}$ & \\
\hline & PASS IT ON \\
\hline
\end{tabular}

Urgency/importance quadrants. 